\section{$\underset{\text { THEMA }}{\text { QS }}$}

\title{
A Contextualização no Ensino de Ciências na Visão de Professores da Educação Básica
}

\section{The Contextualization in Science Teaching from the Standpoint of Basic Education Teachers}

Jucelino Cortez ${ }^{1}$; Luiz Marcelo Darroz ${ }^{2}$

\begin{abstract}
RESUMO
O presente trabalho faz o relato dos procedimentos e dos resultados obtidos com uma pesquisa realizada junto a um grupo de professores da educação básica da rede pública de um município do Rio Grande do Sul. Procuramos com esta ação, utilizando entrevistas semiestruturadas, identificar quais as concepções acerca da contextualização no ensino de ciências, bem como destacar quais os fatores que prejudicam ou contribuem para esta prática. Os depoimentos dos entrevistados foram tratados utilizando-se da Análise Textual Discursiva, método este que balizou a categorização dos dados obtidos nas entrevistas, permitindo assim, atingir nosso objetivo principal que consiste em oferecermos apontamentos motivadores de futuras reflexões acerca da contextualização no ensino das ciências.
\end{abstract}

Palavras-chave: Ensino de Ciências; Contextualização; Educação Básica.

\begin{abstract}
The present work reports the procedures and results obtained with a research performed along a group of teachers of the public basic education of a city in the state of Rio Grande do Sul, Brazil. Using semi-structured interviews, we sought to identify the conceptions around the contextualization in science teaching, as well as to highlight the harmful and contributing factors of this practice. The testimonials of respondents were treated with the Discursive Textual Analysis, which method marked out the classification of data obtained in the interviews, thus allowing reaching our main objective that consists of offering motivating notes for future reflections around the contextualization in science teaching.
\end{abstract}

Keywords: Science Teaching; Contextualization; Basic Education.

1;2 UPF - Universidade de Passo Fundo, Passo Fundo/RS - Brasil. 


\section{INTRODUÇÃO}

A Educação Básica no Brasil vivencia um lento processo de transformação, iniciado a mais de sessenta anos. Para Santos (2007), estas ações, de uma forma muito gradual, começaram a alterar o papel da escola diante da sociedade, procurando aprimorar o perfil que estas instituições portavam como formadoras de pequenos cientistas. Para este teórico, a partir dos anos setenta, a educação formal começa a valorizar a compreensão das ciências, relacionando-a com o contexto econômico e social.

Nesta perspectiva, o governo federal, através do Ministério da Educação, publica, em 1996, a Lei de Diretrizes e Bases da Educação Nacional (LDB) (BRASIL, 1996), oferecendo novos rumos para a educação básica. A partir de então, diversos documentos governamentais como os Parâmetros Curriculares Nacionais (PCNs) (BRASIL, 1999) e as Diretrizes Curriculares Nacionais (DCNs) (BRASIL, 2013), são divulgados, valorizando um processo educacional contextualizado e interdisciplinar.

Daí a necessidade de se estimularem novas formas de organização dos componentes curriculares dispondo-os em eixos temáticos, que são considerados eixos fundantes, pois conferem relevância ao currículo. Desse modo, no projeto político-pedagógico, a comunidade educacional deve engendrar o entrelaçamento entre trabalho, ciência, tecnologia, cultura e arte, por meio de atividades próprias às características da etapa de desenvolvimento humano do escolar a que se destinarem, prevendo: [...] a organização dos tempos e dos espaços com ações efetivas de interdisciplinaridade e contextualização dos conhecimentos (BRASIL, 2013, p.50).

Todas estas orientações, dos diferentes documentos, procuram alterar uma realidade educacional, facilmente encontrada, com características bancárias de ensino fragmentado e descontextualizado. Segundo Paulo Freire:

[...] as relações educador-educando na escola tradicional são fundamentalmente narradoras, dissertativas, cabendo ao educador a tarefa de "encher" os educandos com os conteúdos de sua narração, numa concepção "bancária" da educação (FREIRE, 2009, p.67).

Corroborando com estas orientações, teóricos como Lutfi (1992), Bueno (1996), Santos e Mortimer (1999), González (2004), Machado (2004), Wartha e Alário (2005) e Ricardo (2005) voltam seus olhares para o ensino contextualizado e para as discussões sobre a contextualização nas ciências. Segundo Bueno (1996), o termo "contextualização" deriva do termo "contexto" e significa o enquadramento sintagmático de uma unidade do discurso ou uma situação de comunicação. Para Machado (2004), o termo deveria ser "contextuação", considerando o real sentido associado à ideia, ao considerar a aproximação do conteúdo formal com a realidade de vida do educando. Ainda, para este autor, a contextualização no ensino é foco de vários debates e entendê-la, em suas concepções epistemológicas e filosóficas, facilita seu uso como metodologia.

E é esta a temática que justifica nossa pesquisa, admitindo que este assunto é pertinente junto à educação básica, ao estar presente nos documentos oficiais e também, por considerar a visão do teórico Wildson L. P. dos Santos (2007), ao afirmar que a contextualização não é uma realidade concreta nos meios escolares. Segundo este autor, percebe-se que "o ensino de ciências, na maioria de nossas escolas, vem sendo trabalhado de forma descontextualizada da sociedade e de forma dogmática" (SANTOS, 2007, p. 4). 
O objetivo desta pesquisa consiste em identificarmos junto aos professores da educação básica, de uma pequena cidade do Rio Grande do Sul, quais são suas concepções sobre contextualização no ensino e quais os fatores que afetam o uso desta em suas aulas. Acreditamos que com isso, poderemos proporcionar discussões sobre o tema, melhorando assim as possibilidades de qualificarmos o processo educativo.

Para atingir esta proposta, realizamos uma pesquisa qualitativa, com procedimento de estudo de caso (GERHARDT E SILVEIRA, 2009), promovendo junto aos professores uma entrevista semiestruturada (Triviños, 2012), tratando os depoimentos com o uso da Análise Textual Discursiva (Moraes, 2003). Desta análise, apresentamos nossas considerações conforme categorias escolhidas a priori, apresentadas por González (2004), ao trazer a tona uma discussão conceitual sobre as dimensões da contextualização.

Após esta introdução, apresentamos a metodologia seguida, apontando, na sequência, os resultados obtidos com a análise escolhida, tecendo, por fim, nossas considerações finais.

\section{METODOLOGIA DAS ATIVIDADES}

Escolhemos para esta pesquisa uma abordagem qualitativa aplicada, por tratar-se de um aprofundamento na compreensão de uma situação prática, sem buscar representatividade numérica. O procedimento foi um estudo de caso, considerando que trabalhamos com um corpo de sujeitos pertencentes a uma região específica, procurando entender aspectos e características, sem a intenção de intervir (GERHARDT E SILVEIRA, 2009).

Foram entrevistados, durante a primeira semana de maio do corrente ano, doze professores de educação básica, da área de ciências da natureza, sendo oito da rede estadual e quatro da rede municipal. Destes doze, seis trabalham na rede pública e seis na rede privada. Não diferenciamos estes profissionais em nosso estudo, mantendo anonimato das entrevistas, citando-os em seus depoimentos, como professor 1 (P1), professor $2(\mathrm{P} 2)$ e assim por diante.

A entrevista era do tipo semiestruturada considerando que o uso dessa modalidade permite que o entrevistado ultrapasse formalidades, construindo sua própria explicação para os fenômenos, enriquecendo a investigação (TRIVIÑOS, 2012). Durante esta ação, os professores foram convidados a uma conversa informal, realizada separadamente, em diferentes oportunidades, sobre ensino e contextualização, diálogo este que seria pautado por três perguntas que, em nosso ver, serviriam de norteamento para o relato e permitiriam aos entrevistados, expressar quais suas concepções sobre o tema.

As perguntas foram:

1 - Na sua concepção, o que é contextualização no ensino das ciências?

2 - Em sua prática pedagógica, você utiliza a contextualização? Quando? Com que frequência?

3 - Em sua prática pedagógica, encontra possibilidades para fazer a contextualização? Quais fatores contribuem e quais atrapalham para o uso desta? 
Depois de obtermos estes doze textos, passamos para a fase do tratamento dos dados obtidos. Utilizamos a Análise Textual discursiva (ATD), conforme Moraes (2003) e Moraes e Galiazzi (2006).

A ATD, segundo Moraes e Galiazzi (2006), transita entre a análise do discurso e a análise do conteúdo, sendo um procedimento executado em partes distintas. A primeira, conhecida como unitarização ganha sentido dentro da pesquisa quando encaminha o texto para a categorização, em que as unidades de significado são agrupadas de acordo com critérios semânticos, isto é, fragmentos que explicitam compreensões semelhantes.

A análise textual discursiva é descrita como um processo que se inicia com uma unitarização em que os textos são separados em unidades de significado. Estas unidades por si mesmas podem gerar outros conjuntos de unidades oriundas da interlocução empírica, da interlocução teórica e das interpretações feitas pelo pesquisador (MORAES E GALIAZZI, 2003 , p.118).

Na sequência, passamos para a próxima etapa, conhecida como categorização. Nesta fase, busca-se identificar relações entre as unidades base, agrupando-as em novos conjuntos denominados como categorias. Estas podem ser eleitas a priori ou emergentes. As categorias a priori são categorias já existentes na literatura e que o pesquisador utiliza para enquadrar seus fragmentos; categorias emergentes são aquelas que surgem a partir da análise do corpus, ou seja, o pesquisador não as conhece de antemão, e sim as constrói a partir da análise dos dados recolhidos durante a pesquisa, ou de algum material já existente que se propõe a analisar. As mistas, como o próprio nome indica, mesclam as duas categorias anteriormente mencionadas.

Neste sentido, escolhemos, a priori, as categorias que estão presentes no trabalho de González (2004), que resgatam uma discussão mais conceitual sobre o que é contextualização. Para este autor, a contextualização abarca três dimensões: a histórica, a metodológica e a sócio-ambiental.

A visão histórica refere-se à abordagem de como surgiram as teorias e os conceitos científicos, valorizando a realidade histórica dos cientistas e suas condições para o desenvolvimento destas teorias. Esta dimensão possui um perfil aproblemático da ciência, considerando esta como uma verdade absoluta e inquestionável.

A concepção metodológica infere que os conteúdos estão relacionados com uma série de outros eventos, abrangendo áreas distintas e, portanto, precisam ser tratados, a fim de permitir para o educando uma visão completa do conhecimento, de maneira conectada aos fins, sem deixar a ideia de que o conteúdo está em determinado currículo somente por estar.

A última dimensão é a sócio-ambiental, que está vinculada à ideia de relacionar a utilidade do conhecimento científico em nosso entorno, avaliando e considerando as implicações da ciência na sociedade e as influências que a sociedade pode e deve fazer na evolução do conhecimento. Esta dimensão carrega muitos traços que são comuns no enfoque Ciência - Tecnologia - Sociedade, sendo defendida por autores como Santos e Mortimer (2002), Auler (2001) e Cachapuz e seus colaboradores (2004).

Por fim, com esta nova formatação, procura-se construir o chamado metatexto resultante, expressando o conjunto de argumentos que, na visão do autor, permitem a compreensão dos fenômenos investigados (MORAES, 2003). 


\section{ANÁLISE DOS RESULTADOS}

Após realizarmos as entrevistas, passamos à fragmentação das respostas, procurando identificar as relações entre as categorias anteriormente definidas e os depoimentos colhidos junto aos professores. Percebemos que alguns comentários transitam entre as categorias, dificultando, em parte, a classificação destes. Mesmo assim, algumas características são comuns a todos os depoimentos, dando certo perfil para o grupo de professores. Descreveremos, na sequência, conforme as categorias, as observações pertinentes construídas a partir das respostas dos entrevistados.

\subsection{DIMENSÃO HISTÓRICA}

Esta dimensão praticamente não esteve presente na fala dos entrevistados, sendo que somente dois participantes citaram em alguns momentos da conversa, ideias que nos remetiam a esta concepção.

Na visão de um destes, contextualizar é "abordar conteúdos considerando sua origem, sua evolução, sua história" (P12) e também, "é considerar e explicar para os alunos que tudo muda, tudo evolui. Então contextualizar significa saber que o que aprendemos é assim hoje, mas ontem talvez não sabíamos ou não considerávamos como agora" (P12). Percebe-se na opinião deste entrevistado, em alguns pontos, características da dimensão histórica conceituada por González (2004), quando relaciona a contextualização com o desenvolvimento das teorias e com a história das ciências. Também nesta fala, identifica-se uma visão crítica da evolução científica e da utilização desta ciência, diferente da visão de ciência pronta e acabada que esta dimensão propõe. O participante P12 aponta a ciência como um processo inacabado, influenciado pela sociedade, em constante superação de conhecimentos.

Na visão do entrevistado P11: "contextualizar é explicar para o aluno que tudo evolui, inclusive a ciência". "Esta evolução se dá dentro de um contexto histórico que todos devem conhecer; alunos e professores". Nesta proposição também identificamos a dimensão histórica e, segundo este professor, "devemos usar sempre deste recurso para que nosso aluno tenha visão real de como as coisas acontecem".

Estes dois participantes ainda destacam os principais fatores que dificultam a contextualização como sendo "a falta de interesse por parte de muitos professores em conhecer a história da ciência" e "a quase inexistência de cursos de formação para educadores que ensine a relacionar a história da ciência". Para o entrevistado P9, "precisamos ter boa vontade para pesquisar o contexto das descobertas, mas é difícil pela grande carga horária que possuímos".

\subsection{DIMENSÃO METODOLÓGICA}

Esta dimensão aparece na maioria das entrevistas, tanto nas tentativas de explicar o que é contextualização, quanto no uso desta estratégia. Ainda é possível identificá-la nas respostas acerca dos fatores que facilitam ou dificultam o uso da contextualização.

Para o participante P9, contextualizar é "relacionar os conteúdos com outras disciplinas, dando sentido completo a eles". Esta mesma concepção aparece no discurso do P10 ao defender que "contextualizar é relacionar os conteúdos de ciências com os conteúdos de outras disciplinas, a fim de proporcionar um entendimento do motivo dos assuntos estarem nos currículos naquele momento". Este propósito 
também é observado na versão do P4 ao afirmar que "contextualizar é localizar no tempo e no espaço os conteúdos e seus fins, para que os alunos saibam o porquê estão estudando tais assuntos".

Quanto à frequência do uso da contextualização, percebe-se também que muitos entrevistados veem o ato de contextualizar associado com o fato de "linkar conteúdos" (P6) e, nesta visão, só o fazem quando "tem tempo suficiente para estabelecer relações entre as matérias" (P4) ou, "quando os conteúdos permitem a relação, então tentamos fazer a contextualização" (P2). Ainda, relacionada à dimensão metodológica, percebe-se em muitos depoimentos, que as principais dificuldades para o uso da contextualização estão relacionadas à "falta de tempo para preparar aulas envolvendo outras disciplinas" (P8), à "falta de conhecimento sobre outras áreas" (P5), "à necessidade de vencer conteúdos" (P8) e, na visão do professor P10 e do P4: "falta envolvimento, participação e apoio por parte de: direções, que não querem muita bagunça na escola; colegas professores, que não querem inovações" (P10) e por parte de "alguns alunos que querem informações prontas para decorar" (P4).

Mesmo com esta lista de dificuldades para desenvolver esta dimensão da contextualização com características interdisciplinares, é quase unânime a indicação referindo-se à sua dimensão metodológica como necessária e facilitada. Atualmente, para alguns entrevistados, esta facilidade estaria relacionada aos "recursos tecnológicos como filmes e animações" (P1) e "às redes sociais que nos permitem a troca de ideias e informações" (P3).

\subsection{DIMENSÃO SÓCIO-AMBIENTAL}

Esta dimensão de contextualização também é muito presente no discurso dos entrevistados, sendo que em muitos casos, aparece junto com a dimensão metodológica, dificultando a identificação e a diferenciação destas.

Quando os entrevistados discorriam sobre o conceito do termo contextualização, em muitos casos surgiam citações como: "é trabalhar o conteúdo próximo à realidade do aluno" (P1), "é inserir o aluno e sua realidade dentro do conteúdo que pretendemos estudar" (P2), "é usar uma situação prática para começar um conteúdo" (P3) e em várias outras falas tem-se: "é relacionar o conteúdo com o cotidiano" (P5), (P8), (P10), (P11).

Ao abordarmos, durante a entrevista, a frequência com que esta contextualização é feita, na visão destes professores, encontramos também fortes características desta dimensão sócio-ambiental: "faço contextualização quando tenho uma situação-problema, que muitas vezes está relacionada com o dia-a-dia do aluno" (P1) e "é possível contextualizar alguns conteúdos que nos permitem relacionar o cotidiano e as situações reais da vida dos alunos" (P7). Também identificamos e relacionamos com esta dimensão, que alguns entrevistados acreditam na existência de poucas oportunidades para a contextualização, afirmando que "poucos conteúdos de ciências permitem a contextualização" (P5), logo, "na maioria dos conteúdos seguimos o plano e o livro texto" (P3).

Quanto à busca pelos fatores que geram dificuldades ou que facilitam no uso da contextualização, identificamos a concepção sócio-ambiental na maioria dos discursos, tanto de forma explícita, quando o professor cita que "faz contextualização quando tem uma situação-problema, que muitas vezes está relacionada com o dia-a-dia do aluno", quanto de forma indireta, quando o professor narra que contextualizar é "inserir o aluno e sua realidade dentro do conteúdo". 
$\mathrm{Na}$ visão dos participantes, são fatores que contribuem para a contextualização: "o acesso à informação sobre a realidade local através dos múltiplos meios de comunicação" (P1), "alguns livros oferecem questões polêmicas e recursos multimídia que valorizam discussões" (P11) e "em todas as turmas existem alunos críticos e questionadores que levantam situações que permitem, ao bom professor, a oportunidade de contextualizar" (P12).

Para os participantes P1, P2, P6, P7 e P8, a contextualização está relacionada com "situaçõesproblema" e, utilizar este "recurso" "demanda tempo que geralmente não dispomos" (P1), "implica em conhecermos a família, o trabalho e a realidade social do aluno" (P7) e "obriga o professor a ir além do mais simples, que seria somente passar conteúdos no quadro" (P2).

\section{CONSIDERAÇÕES FINAIS}

Abordar a contextualização no ensino das ciências, procurando identificar concepções e dimensões acerca do conceito e dos fatores que permeiam a realidade escolar, parecia de início, uma tarefa relativamente simples, considerando que o termo está em voga na educação, que todos os entrevistados estão exercendo suas funções em sala de aula e participando de cursos de formação continuada oferecido pelas secretarias de educação.

Mas quando começamos a identificar as diferentes dimensões que os professores têm sobre contextualização e sobre os fatores que eles julgam interferir no seu uso, desvelamos algumas concepções, por parte dos entrevistados, capaz de instigar análises que, com certeza, motivarão reflexões acerca das ações e das condições consideradas por estes profissionais em suas práticas.

Percebemos que, na maioria dos casos, os professores não veem a ciência como algo sendo construído junto e influenciado pela sociedade, e nem consideram o ambiente em que as pesquisas científicas emergem, sendo que, somente dois entrevistados teceram comentários relacionados à dimensão histórica, remetendo os conteúdos com o contexto histórico das descobertas científicas que são abordadas em um determinado tema.

Identificamos também, nesta pesquisa, que a maioria dos entrevistados concebe a contextualização pela dimensão metodológica, atribuindo a esta prática a "relação entre conteúdos e disciplinas". Nesta mesma categoria, percebe-se, no discurso dos professores, um forte compromisso com o conteúdo que deve ser dado e com o tempo para execução do mesmo, sendo que, muitos entrevistados citam, como fator de dificuldade para fazer a contextualização, o escasso tempo de preparação de aulas e de flexibilidade para cumprimento dos planos de ensino.

Em menor número, mas também presente em muitos depoimentos, a dimensão sócio-ambiental é citada pelos entrevistados. Vários professores abordaram a contextualização como sendo "a inserção de situações reais e práticas" no processo de ensino, destacando ainda, como fator de dificuldade, que "alguns conteúdos permitem a contextualização e outros não". Nesta categoria ainda identificamos na fala dos entrevistados, os reveses causados pelo pouco tempo para utilização deste "recurso", pois para alguns destes profissionais (P1, P7 e P2), estas ações implicam em "ir além do mais simples, que seria somente passar conteúdos". 
Diante do exposto, consideramos ter atingido nosso objetivo, ao fornecer dados que possibilitarão discussões acerca do que concebemos sobre contextualização, dos fatores que são pertinentes no seu uso e das dificuldades enfrentadas pelos entrevistados.

Estes apontamentos não visam julgar opiniões certas ou erradas sobre o tema de estudo, nem considerar se os fatores apontados são realmente plausíveis. Consideramos que o ensino é um processo vivo, em evolução, sendo a busca pela qualidade e pela melhoria dos processos pedagógicos, uma estrada a ser trilhada no sentido de levar os estudantes à completa compreensão do mundo no qual estão inseridos.

\section{REFERÊNCIAS BIBLIOGRÁFICAS}

AULER, D. Alfabetização Científico-Tecnológica para quê? Ensaio - Pesquisa em Educação em Ciências. Belo Horizonte: v.3, n.2, 2001.

BRASIL. Congresso Nacional. Lei de diretrizes e bases da educação nacional. Lei no 9394/96. Publicada no diário Oficial da União de 17 de dezembro de 1996.

BRASIL. Parâmetros Curriculares Nacionais do Ensino Médio. Brasília: MEC;SEMTEC, 1999

BRASIL. Ministério da Educação. Secretaria de Educação Básica. Diretrizes Curriculares Nacionais Gerais da Educação Básica; Ministério da Educação. Secretaria de Educação Básica. Diretoria de Currículos e Educação Integral. Brasília: MEC, SEB, DICEI, 2013.

BUENO, F.S. Minidicionário da Língua Portuguesa. São Paulo. Ed.FTD, 1996.

CACHAPUZ, Antonio; PRAIA, João; JORGE, Manoela; Da Educação em Ciência às Orientações para o Ensino das Ciências: Um Repensar Epistemológico; Ciência \& Educação, v. 10, n. 3, p. 363-381, 2004.

FREIRE, P. Pedagogia do oprimido. São Paulo: Paz e Terra, 2009.

GERHARDT, Tatiana E. e SILVEIRA, Denise T.; Métodos de pesquisa / Universidade Aberta do Brasil - UAB/UFRGS e pelo Curso de Graduação Tecnológica - Planejamento e Gestão para o Desenvolvimento Rural da SEAD/UFRGS. - Porto Alegre: Editora da UFRGS, 2009

GONZÁLEZ, Carlos Vázquez. Reflexiones y Ejemplos de Situaciones Didácticas para uma Adecuada Contextualización de los Contenidos Científicos en el Proceso de Enseñanza. Revista Eureka sobre Enseñanza y Divulgación de las Ciencias. v.1, n. 3, 2004.

LUTFI, Mansur. Ferrados e cromados: produção social e apropriação privada do conhecimento químico. Ijuí: Unijuí, 1992.

MACHADO, N. J. Educação: projetos e valores. 5 edição. São Paulo, Ed. Escrituras: 2004.

MORAES, Roque. Uma Tempestade de Luz: A Compreensão Possibilitada pela Análise Textual Discursiva. Ciência \& Educação, v. 9, n. 2, p. 191-211, 2003

MORAES, Roque; GALIAZZI, Maria do Carmo. Análise Textual Discursiva: Processo Reconstrutivo de Múltiplas Faces. Ciência \& Educação, v. 12, n. 1, p. 117-128, 2006. 
RICARDO. Elio C.; Competências Interdisciplinaridade e contextualização: dos Parâmetros Curriculares Nacionais a uma compreensão para o Ensino de Ciências. Tese (doutorado em Educação Científica e Tecnológica) - Centro de Ciências Físicas e Matemáticas, Centro de Ciências da Educação, Centro de Ciências Biológicas, Universidade Federal de Santa Catarina, Florianópolis, 2005.

SANTOS, Wildson L. P. e MORTIMER, Eduardo F.; Concepções de professores sobre contextualização social do ensino de química e ciências. In: 54 Reunião Anual da Sociedade Brasileira de Química, 22, 1999. Anais Poços de Caldas: Sociedade Brasileira de Química, 1999.

SANTOS, Wildson L. P. e; MORTIMER, Eduardo F.; Uma análise de pressupostos teóricos da abordagem C-T-S (Ciência - Tecnologia - Sociedade) no contexto da educação brasileira. Ensaio: Pesquisa em Educação em Ciências, Belo Horizonte, v. 2, n. 2, p. 110-132, 2002.

SANTOS, Wildson L. P.; Contextualização no Ensino de Ciências por Meio de Temas Cts em uma Perspectiva Crítica. Ciência \& Ensino, vol. 1, número especial, novembro de 2007

TRIVIÑOS, Augusto N. S.; Introdução à pesquisa em ciências sociais: a pesquisa qualitativa em educação. São Paulo: Atlas, 2012.

WARTHA, Edson José; ALÁRIO, Adelaide Faljoni. A contextualização no Ensino de Química através do livro didático. Química Nova na Escola, São Paulo, vol.22, n.22, p.42-47, 2005. 